\title{
Entre o dizer e o mostrar: a transcrição como modalidade de enunciação
}

\author{
Valdir do Nascimento Flores
}

RESUMO: Selon les présupposés théoriques de l'auteur, l'analyse des relations énonciatives est développée avec le propos de montrer comment la linguistique de l'énonciation peut étudier la singularité de la transcription. Cet article propose une forme d' approche de la transcription.

PALAVRAS-CHAVE: Enunciação; Transcrição; Corpus.

\section{INTRODUÇÃO}

É fato comum que a lingüística, em suas mais distintas versões, quando trabalha com corpus de natureza falada, utiliza recursos de transcrição, normalmente, entendidos como formas de representação gráfica, mesmo que parcial, dos sons da língua. Tais recursos são variados e constituídos por sistemas de símbolos especiais que, em tese, representam o quadro teórico no qual a pesquisa está inserida. Assim é que há diferentes sistemas de transcrição que atendem a necessidades específicas (fonéticas, fonológicas, sintáticas, conversacionais, variacionais etc.) e diferentes expectativas a respeito do que deve ser preservado na passagem da fala ao transcrito.

Esse tema não tem recebido atenção por parte dos autores do campo da Enunciação. O que se percebe é que, por um lado, as pesquisas concernentes a esse campo, com raras exceções, não explicitam aspectos metodológicos relativos aos mecanismos de tratamento dos dados. Por outro lado, isso se faz acompanhar de certa vagueza na compreensão, por parte de alguns, a

Valdir do Nascimento Flores é professor de Língua Portuguesa do Instituto de Letras da Universidade Federal do Rio Grande do Sul. Pesquisador do CNPq. 
respeito de aspectos epistemológicos e metodológicos referentes a análises enunciativas da linguagem. Assim, tem sido comum, no meio especializado, encontrar quem indague: como se faz uma análise enunciativa da linguagem? Como é a metodologia da teoria da enunciação? O que é um dado na perspectiva enunciativa? Como se fazem transcrições compatíveis com a visão enunciativa acerca da linguagem?

A explicitação desses pontos impõe-se como necessidade teórica. Evidentemente, este trabalho não tem a pretensão de tratá-los integralmente. O interesse aqui é apenas em um ponto: a transcrição. Os demais tópi$\cos$ não serão mais do que tangenciados na medida em que isso se fizer necessário para abordar o tema em foco. Dessa forma, este trabalho, a partir do referencial da Lingüística da Enunciação (cf. Flores; Teixeira, 2005) estuda a transcrição como um ato de enunciação, portanto, como algo da ordem da singularidade.

Vale lembrar, contudo, que, quando se trabalha no escopo da Enunciação, necessariamente deve-se tomar uma posição a respeito do sujeito que enuncia. Pode-se estudá-lo, no mínimo, em duas direções: a) como marcas delimitadas no sistema lingüístico (é o shifter de Roman Jakobson, é o aparelho formal da enunciação de Émile Benveniste, são as operações de Antoine Culioli); b) como instância de fala - não redutível às marcas lingüísticas mesmo que não prescinda delas - cuja abordagem transcende os limites da lingüística e impõe recurso a exterioridades teóricas à linguística. Este trabalho alinha-se a esta segunda direção. Logo, versa sobre transcrição por um viés enunciativo e convoca exterioridades teóricas à lingüística, qual seja, a psicanálise lacaniana.

Em suma, considerando-se que a enunciaç̃o é um ato que não pode ser visto desvinculadamente do sujeito que a produz e considerando-se a clivagm estrutural do sujeito, cabe dizer que a transcrição é, nesse caso, um ato de enunciação em que o "dado" a ser transcrito tem seu estatuto enunciativo alterado. A transcrição é, por esse viés, uma enunciação sobre outra enunciação. É, portanto, ato submetido à efemeridade da enunciação que, por sua vez, está na dependência da impossibilidade de que tudo se diga, constitutiva da clivagem do sujeito' ${ }^{1}$.

1 Jean Allouch, em Letra a letra: transcrever, traduzir, transliterar, também reflete sobre a trans$'$ Jean Allouch, em Letra a letra: ranscrever, crição no escopo da psicanalise lacaniana. No entanto, o can verá trata-se de Ludwig Wittgenstein e de Émile Benveniste), embora não oposto ao de Allouch, não pode ser a ele atribuído. A partir da reflexão de Allouch e na relação com enunciação, é náo pode ser a ele atroposto em: SURREAUX, L. M. Linguagem, sintoma e clínica em clínica de linguagem. Tese de doutorado. Porto Alegre, IL/UFRGS, 2006
Para dar consistência à passagem de uma instância enunciativa à outra - tal como definida na obra de Émile Benveniste - recorre-se aqui à distinção entre dizer e mostrar presente no Wittgenstein do Tractatus LogicoPhilosophicus, e retomada por Jacques Lacan, em especial, a partir do Seminário XX, mais ainda. Enfim, sugere-se que a transcrição compõe dois tempos na enunciação que envolve a passagem do mostrar ao dizer: a) sendo, de um lado, da ordem do mostrar, a transcrição da cena e, b) de outro, da ordem do dizer, a transcrição como uma outra enunciação.

Para facilitar o entendimento do que se pretende, em primeiro lugar, serão apresentados alguns pontos da distinção entre dizer e mostrar estabelecida por Ludwig Wittgenstein (cf. 1); em segundo lugar, far-se-á menção à forma com Jacques Lacan opera com a distinção (cf. 2); em terceiro lugar, busca-se explicitar o funcionamento enunciativo da distinção quanto aos aspectos da transcrição (cf. 3).

Cabe ainda uma recomendação: pode-se evitar a leitura das duas primeiras partes do texto - uma vez que nada mais é que uma retomada maçante para aqueles que não desconhecem o percurso - e passarse de imediato à terceira parte, onde é formulada a proposta da transcrição como uma modalidade de enunciação obtida a partir da distinção dizer/mostrar.

\section{DIZER E MOSTRAR}

A filosofia de Wittgenstein, em especial, no Tractatus busca, na análise da linguagem, uma forma de realização da filosofia, através do estudo semântico da proposição. Um de seus objetivos ${ }^{2}$ é propor uma análise da linguagem que permita compreendê-la a partir de uma lógica interna, na relação desta com os fatos. Diz o filósofo:

O fim da filosofia é o esclarecimento lógico dos pensamentos. A filosofia não é uma teoria, mas uma atividade. Uma obra filosófica consiste essencialmente em elucidações. O resultado não são 'proposições filosóficas', mas é tornar proposições claras. Cumpre à filosofia tornar claros e delimitar precisamente os pensamentos, antes como que turvos e indistintos. (Tractatus, 4.112).

O leitor interessado nos detalhes do sistema teórico de Wittgenstein pode reportar-se aos textos de Russell (1993), Giannotti (1995), L.H.L. Santos (1993) e outros, referidos em nota e em bibliografia anexa.

Organon, Porto Alegre, $n^{\circledR} 40 / 41$, janeiro-dezembro, 2006, p. 61-75 
1.1 a figuração representa logicamente a situação (existência e inexistência de estados de coisas);

1.2 a figuração é um modelo da realidade;

1.3 na figuração, os objetos correspondem aos elementos da figuração;

1.3.1 na figuração os elementos substituem os objetos;

1.4 A figuração é um fato.

Considerando-se que tanto as sentenças verdadeiras como as falsas (as proposições) dizem um estado de coisas (afiguração dos fatos) e têm algo em comum entre si e delas com o fato que elas afiguram, conclui-se pela idéia de que ambas compartilham algo com o fato. Wittgenstein chama de "forma de afiguração 5 " a este elemento comum: "O que a figuração deve ter em comum com a realidade para poder afigurá-la à sua maneira - correta ou falsamente - é sua forma de afiguração" (Tractatus, 2.17).

Qualquer que seja a forma de afiguração, ela sempre deve ter uma forma lógica comum com a realidade, isto é, a forma da realidade (Tractatus 2.18). Essa forma da realidade geral, independentemente do ponto de vista do qual o objeto é afigurado, é o mínimo necessário para que haja afiguração. Nesse sentido qualquer afiguração (entre elas as proposições) é uma afiguração lógica, sendo que a estrutura lógica é a forma mais geral de afiguração, logo, condição de qualquer dizer.

Russell diz, em sua Introdução, que a representação do fato pela sentença depende dos sinais que nela estão, entretanto, as formas lógicas não são representadas por sinais “... mas estão presentes elas próprias, tanto na proposição como no fato.” (p.116), não podendo, contudo, representarem-se. A esse respeito diz Wittgenstein: "Sua forma de afiguração, porém, a figuração não pode afigurar; ela a exibe." (Tractatus, 2.172) [sublinhei]. Ou ainda:

2. A figuração tem em comum com a realidade a forma de afiguração; 2.1 a afiguracão afigura toda a realidade cuja forma ela tenha;

2.2 a forma de afiguração não pode ela ser afigurada, somente exibida ${ }^{6}$;

'Em alguns momentos os Tractatus fala em "forma de representação" para referir o que pode ser entendido como "forma de afiguração": "a figuração, porém, não pode colocar-se fora de sua forma de representação" (Tractatus 2.174)

"Apenas uma observação explicativa: o termo "exibido", utilizado no parágrafo anterior, tem o mesmo sentido de "mostrado", neste. Conforme as traduções que consultei "exibido" é utilizado por Wittgenstein no corpo do Tractatus, mas na introdução feita por Russel o termo e mesmo "mostrado".

${ }^{3}$ Ducrot (1984) enfatiza que as pesquisas de Wittgenstein, indiretamente, dizem respeito à linguagem vulgar. Wittgenstein, a exemplo dos neopositivistas do Circulo de Viena (entre eles Carnap), desconsidera, nesse momento, a linguagem vulgar, devido à impossibilidade de dizer o mundo de forma rigorosa. Estudar as condiçoes de sosstendido já que a linguaimplica o estudo da linguagem vulgar, entretanto, a ela pode "refletir sobre as condições que gem lógica não é indiferente à vulgar. Conse ́e, pois, indiretamente, refletir sobre a linguagem vulgar." (Ducrot, 1984:471).

${ }^{4}$ Na verdade, os Tractatus é organizado em proposições, 7 ao todo, constituídas por proposicões subseqüentes, numeradas em decimal. 
2.3 a figuração representa o objeto correta ou incorretamente;

2.4 A figuração não está fora de sua forma de representação;

3. Se a forma de afiguração é a forma lógica, a figuração é figuração lógica.

Russell, no final da Introdução, formula uma objeção ao Tractatus nos seguintes termos: a atitude mística de Wittgenstein relativamente ao que não pode ser dito deriva da doutrina lógica, segundo a qual a proposição seria uma figuracão (verdadeira ou falsa) do fato e entre eles haveria uma estrutura comum. Tal estrutura possibilita a figuração do fato, mas não pode ser expressa em palavras, já que é uma estrutura de palavras da mesma forma que é a dos fatos aos quais ela se refere. A conclusão de Bertrand Russell é formulada com extrema elegância e mesmo genialidade: "o que provoca hesitação é o fato de que o Sr. Wittgenstein, no final das contas, consegue dizer uma porção de coisas sobre o que não pode ser dito, sugerindo assim a um leitor cético que possivelmente haja escapatória através de uma hierarquia de linguagens ou alguma outra saída." (Russell, In: Tractatus, 1993: 127).

Esse raciocínio é suficiente para pontuar que a forma lógica constitui o que não pode ser dito. A atitude mística a que se refere Russell diz respeito ao fato de a tese de Wittgenstein conduzi-lo a negar que a forma lógica de afiguração possa ela mesma ser afigurada. Eis o elemento místico do qual fala Russell. Para chegar a esse ponto, Wittgenstein faz uma distinção fundamental entre dois modos de a proposição representar a realidade. De um lado, o mostrado, de outro o dito.

Em outros termos:

4. A proposição pode representar a realidade, mas não pode representar a forma lógica que tem em comum com ela para poder representá-la;

4.1 O que se exprime na linguagem não pode ser representado por meio dela;

4.1.1 A proposição mostra a forma lógica da realidade.

Se não há como a forma lógica ser expressa em proposições, mas apenas mostrada, então a fórmula "O que pode ser mostrado não pode ser dito." (Tractatus, 4.121) é a síntese da oposição dito/mostrado. "Há por certo o inefável. Isso se mostra, é o Místico" (Tractatus, 6.522) [grifo do autor].

Russell entende tal paradoxo como a possibilidade de pensar numa hierarquia de linguagens. O próprio Russell adianta a contra argumentação de Wittgenstein, dizendo que o místico pode ser mostrado, embora não mesmo assim, Russell confessa seu desconforto. Por

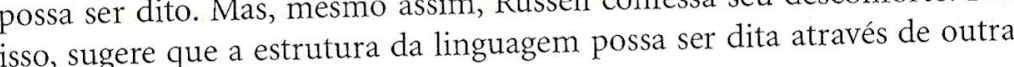

linguagem que, por sua vez, seria dita em uma terceira linguagem. A tal objeção Wittgenstein responderia, segundo Russell, que sua teoria é aplicável à totalidade dessas linguagens. Supor esta resposta permite a Russell dizer que as totalidades sobre as quais é impossível falar são o objeto de misticismo de Wittgenstein.

Isto posto, vale remeter, ainda, à crítica que Michel Meyer elabora, em Lógica, Linguagem e Argumentação (1982), relativamente à problemática entre o que não pode ser dito e a metalinguagem. Meyer apresenta o Tractatus como uma iniciação ao silêncio - "Quando tudo o que pode ser dito já o foi, depois nada resta do que o silêncio" (p. 66)-, para tratar da última afirmação do Tractatus: "Sobre aquilo de que não se pode falar, devese calar." (Tractatus, 7).

Pergunta Meyer: "Como falar da linguagem, captá-la na sua totalidade de linguagem, sem estar fora dela, no indizível? Ê ao indizível que cabe falar-nos da linguagem, e ao sujeito exterior ao mundo, compreender os seus limites?" (Meyer, 1982:68). Obviamente que a opção é pela resposta negativa. Meyer recorre à concepção de sujeito, enquanto condição de possibilidade do todo, para afirmar que os limites do mundo e os correspondentes da linguagem são coextensivos ao ponto de vista do sujeito que fala e, portanto, não podem ser ditos, mas mostrados ${ }^{7}$ " "É essa condição que garante que se possa dizer do mundo (...) que ele é o meu mundo" (Meyer, 1982:69) [grifo do autor].

Nessa interpretação, não existe metalinguagem ${ }^{8}$, o que bem poderia ser uma resposta a Russell. O sujeito que possibilita a totalidade do mundo não pode ser dito, pois este dizer não tem condição que o possibilite. Porém, Meyer questiona se o Tractatus não diz sobre aquilo que só poderia ser mostrado para, enfim, concluir que:

De fato, Wittgenstein esforçou-se ao longo de todo o Tractatus de dizer tudo o que podia sê-lo, e por isso, de dizer como o que não pode sê-lo se mostra: a vida e o sujeito puro enquanto problemas. (Meyer, 1982:70) [grifos do autor].

Corroboram isso as seguintes passagens do Tractatus: "O que não podemos pensar, não podemos pensar; portanto, tampouco podemos dizer o que não podemos pensar." (5.62); "O iujeito que pensa, representa, não existe.'(5.631); "O sujeito não pertence ao mundo, mas é um limite do mundo"(5.632).

"Diz Wittgenstein: "Se eu escrevesse um livro O Mundo tal como o Encontro, nele teria que incluir também um relato sobre meu corpo, e dizer quais membros se submetem à minha ventade e quais não, etc.-este é bem um método para isolar o sujeito, ou melhor, para mostrar que num sentido importante, não há sujeito algum: só dele não poderia se falar neste livro."(Tractatus, 5.631) [grifos do autor]. 


\section{SOBRE AQUILO DE QUE NÃO SE PODE FALAR É POSSÍVEL CA- LAR?}

Evidentemente, a pergunta que serve de título a este item diz respeito ao último aforismo do Tractatus: "Sobre aquilo de que não se pode falar, deve-se calar" (Tractatus, 7). Sobre isso J-C Milner assim se pronuncia: "Wittgenstein teria razão, se somente aquilo de que não podemos falar consentisse em se calar. O ponto é que ele nisso não consente" (Milner: 1996: p. 137). Passa-se, pois, ao tratamento dado a Wittgenstein por Lacan.

Segundo Elisabeth Roudinesco (1994, p. 348-349), com Wittgenstein tem-se uma resposta acerca do que se pode (ou não) exprimir: o que não se pode dizer é um resto, aí incluídos os sentidos éticos e estéticos designados sob a categoria do inefável, do indizível. A incompatibilidade entre o dizer e o mostrar faz com que a filosofia reconheça uma espécie de não-todo que escapa ao todo da formalização: “... essa incompatibilidade entre o dizer e o mostrar interessava a Lacan no ponto em que ele se encontrava em suas próprias pesquisas. Em vez de concluir pela manutenção necessária dos incompatíveis, ele queria, ao contrário, pensar o domínio do inefável integrando nele o não-todo." (p. 348).

A leitura do Tractatus Logico-Philosophicus feita por Lacan, de acordo com Roudinesco (p.361-365), é o que permite ao psicanalista a formulação da noção de matema "como uma escrita do que não se diz, mas que pode se transmitir" (p. 361). Lacan toma Wittgenstein pelo avesso, recusando a separação dos incompatíveis para, através do matema, propor uma formalização transmissível.

Jean Claude Milner também supõe a leitura do Tractatus LogicoPhilosophicus por Lacan ["Que Lacan tenha lido Wittgenstein, isso não está em dúvida" (1996: p. 136)] e detém-se no que chama de "o problema de Wittgenstein". Para Milner, a fronteira real e intransponível entre o dizer e o mostrar concebida por Wittgenstein é tomada por Lacan numa outra lógica: o aforismo "a verdade não se diz toda" não implica que a verdade não se diga; ela se diz, mas não-toda: "a dicotomia de Wittgenstein é barrada pela lógica do parcial, do incompleto, do entre-dois, do heteros: dizer é juntar o que é radicalmente estranho a si mesmo" (p. 137).

O fato é que Lacan leu Wittgenstein e comenta-o no seminário O avesso da psicanálise, Seminário 17, de 1969-1970 (p. 55-58). Lacan refere especialmente os aforismos 6.51,2,3 e 4, onde Wittgenstein trata do enigma e do possivel no campo da ciência. Mas é no Seminário XX, mais ainda que Lacan desenvolve a noção de matema, também derivada da leitura de Wittgenstein. Nesse Seminário, Lacan apresenta as principais características do que en- 
tende por nó borromeano. Em linhas gerais, at ravés dessa noção, Lacan busca mostrar que a articulação do Real, Simbólico e Imaginário é indissolúvel. O nó borromeano ilustra o fato de que a estrutura é constituída pelos três registros, a partir dos quais a psicanálise concebe o sujeito ${ }^{9}$. Nesse sentido, estrutura inclui o sujeito que é feito dela. Quando Lacan apresentou a teoria dos nós, também apresentou o propósito de percebê-los como uma formalização passível de transmissão. Diz ele: "A formalização matemática é o nosso fim, nosso ideal. Por quê? Porque só ela é matema, quer dizer, capaz de transmitir integralmente." (S. XX, p. 161) [sublinhei]. Com isso queria poder Lacan falar do Real: "Só a matematização atinge um real (...) o real, eu diria, é o mistério do corpo falante, é o mistério do inconsciente." (S. XX, p.178).

Milner (1996), no entanto, interpreta que o nó é refratário a uma matematização integral: "não há matema do matema (...) há apenas o nó que permanece rebelde a uma literalização integral..." (Milner, 1996:132). Em outras palavras, o nó é o próprio Real que não se deixa "topologizar". A conclusão de Milner é pela sobra (lalangue): "De um lado, os nós taciturnos, de outro, a um só tempo disjunto de si mesmo e onipresente, o poema, atestado e abolido por sua própria proliferação." (idem, p.134). A oposição wittgensteiniana dito/mostrado é, enfim, referência para Lacan para falar do matema e do saber que não se transmite. Lacan a interpretou para construir o matema como possibilidade de transmissão da psicanálise, no entanto, é bom lembrar, o matema não prevalece sobre o inconsciente, pois este não pode ser apenas mostrado, já que não cessa de se dizer.

\section{ENTRE O DIZER E O MOSTRAR: A TRANSCRIÇÃO COMO MODA- LIDADE DE ENUNCIAÇÃO}

Feitas as observações acima cabe elencar, ao menos em linhas gerais, a dimensão enunciativa da transcrição tal como aqui está delineada.

1 Princípio geral: recusa-se qualquer possibilidade de articular psicanálise à lingüística se a palavra articulação for tomada no sentido de produção de uma positividade, de algo que estaria no fim de uma bem sucedida soma.

${ }^{9}$ Importa, porém, lembrar que a reflexão de Lacan apenas tem início no Seminário XX, sendo bastante aprofundada em momentos posteriores como no Seminário denominado de R.S. dos anos de 1974-1975.
Mesmo que isso não possa ser devidamente bbordado $^{10}$, importa dizer que, do prisma aqui assumido, não poderia ser diferente: de certa maneira, a ciência - ou qualquer saber que se inscreva na ordem do repetível - recalca o que nela não cabe. $\mathrm{E}$ o inconsciente é o recalcado por excelência das ciências binárias, como diria Dany Robert Dufour. A língua como objeto do saber lingüístico tem existência porque distinguível, porque idêntica a ela mesma, porque isomórfica. A posição da psicanálise em relação a isso é de exterioridade teórica.

2 Essa operação de recalcamento atende à demanda de que um saber possa ser emitido acerca da língua. Há, porém, um ponto de basta (point-decapiton): o sujeito da enunciação, aquele que operaria uma espécie de subversão da isomorfia da relação significante/significado. Eis o ponto que subverte a lógica da imanência: o sujeito. Porém, para dele falar, ao menos na perspectiva teórica aqui assumida, não pode ser ignorada sua clivagem estrutural, uma vez que o sujeito, independentemente da configuração que tenha, transcende os quadros da lingüística; para estudá-lo é necessário convocar exteriores teóricos à lingüística ${ }^{11}$. A psicanálise comparece no campo da lingüística como exterior a este e em função do sujeito da enunciação.

3 A enunciação é o que não se pode desconhecer. Por que a enunciação? Porque ela é de ordem radical, é da instauração de uma efemeridade radical. A enunciação é um conceito geral que só tem sentido para o individual, para cada um (cf. Benveniste, 1988 e 1989).

3.1 A teoria da enunciação de Benveniste aborda a linguagem do ponto de vista da irrepetibilidade. A enunciação é sempre única e irrepetível, porque a cada vez que a língua é enunciada têm-se condições de tempo (agora), espaço (aqui) e pessoa (eu/tu) singulares. Assim, cada análise da linguagem é única também. É da ordem do repetível apenas a organização do sistema da língua.

3.2 Tal irrepetibilidade diz respeito à consideração do sujeito da enunciação - seja enquanto marcas no enunciado, seja enquanto ins-

${ }^{10}$ Os meus posicionamentos acerca das relações entre lingǘstica e psicanálises estão em Estudos da Linguagem e Psicanálise: das (im) possibilidades se elas existem (2006), conferência apresentada por ocasião do II Seminário de pesquisa em Análise do Discurso (SEMAD), UFU, Uberlândia, MG. (no prelo). Ver também: FLORES, V. N. "Lingüística e Psicanálise: o que pode uma dizer à outra”. In: GUEDES, M.; BERLINCK, R.de A.; MURAKAWA, C. de A. A.. (Org.). Teoria e análise lingüísticas: novas trilhas. 1 ed. Araraquara: Laboratório Editorial FCL/ UNESP - Cultura Acadêmica, 2006, v. 1, p. 187-195.

11 Eu remeto a Sujeito da enunciação elou sujeito do enunciado? exterioridade e interioridade teórica no campo da lingüística da enunciação, conferência dada por ocasião do VII CELSUL 2006, em Pelotas, RS (no prelo). 
tância pressuposta de produção do enunciado - como o elemento que permite abordá-la.

3.3 A enunciação está presente na estrutura da língua. Em outras palavras: está previsto na língua o lugar de sua própria irrepetibilidade. A esse mecanismo Émile Benveniste chama de Aparelho formal de esse me a pode-se afirmar a generalidade do específico: é universal (é geral) que todas as línguas tenham dispositivos que permitam sua utilização singular pelos sujeitos, é particular (é específico) a configuração desses sistemas e o uso que os sujeitos fazem deles. 3.4 A fórmula da generalidade do específico não é estranha à psicanálise. A psicanálise ao conceber o inconsciente supôs que existe o inconsciente para todo o sujeito - e isso é uma proposição geral -, no entanto, a estruturação psíquica é algo absolutamente singular.

A transcrição é uma modalidade de enunciação. É ato pelo qual se passa de uma forma à outra, de uma substância à outra. A transcrição é um produto, cujo processo é constituído de dois atos:

4.1 há, em primeiro lugar, uma operação de ciframento. Trata-se de uma escrita com base em algo que não é ela (uma fala, outra escrita, desenho etc.). O ciframento implicado na transcrição é o produto da operação que produz um objeto constituído por um conjunto de caracteres sinais do código escrito ou não. A chave dessa escrita, desse ciframento, é o conjunto das regras de transposição subjacentes aos sinais. A transcrição, como operação de ciframento, não tem valor absoluto, seu valor é relativo ao que tenta transcrever. A operação de ciframento é uma tentativa de burlar o tudo não se diz, já que seu sucesso depende do quanto ela consegue, através de um sistema de notação, manter a integralidade do que é notado. Por essa operação, tenta-se ignorar o impossível da passagem de um sistema a outro.

Isso posto, cabe lembrar que não é propriamente algo novo considerar que na transcrição tudo não se diz. Nos inúmeros sistemas de transcriç̃o, independentemente, do referencial teórico mobilizado, sempre crição, independentemente, do referencial teorico mó determinada pelo há objetivos da análise. Há também clareza acerca quadro teór do distanciamento que existe entre a notação e o notado. No entanto, no quadro aqui mobilizado, a operação de ciframento responde por um primeiro tempo do transcrever como ato de enunciação, o do mostrar o da afiguração do objeto.

A transcrição é, naquilo que ela depende da operação de ciframento, um mostrado que tem um sistema de implicação, o qual farei corresponder pari passu com as três primeiras partes do sistema de implicação derivado da leitura do Tractatus desenvolvido acima.
A. transcreve-se o fato;

A.1 a transcrição representa logicamente a situação (existência e inexistência de estados de coisas);

A.2 a transcrição é um modelo da realidade;

A.3 na transcrição, os objetos correspondem aos elementos da transcrição;

A.3.1 na transcrição os elementos substituem os objetos;

A.4 a transcrição é um fato.

B A transcrição tem em comum com a realidade a forma de transcrição;

B.1 a transcrição transcreve toda a realidade cuja forma ela tenha;

B.2 a forma de transcrição não pode ela ser transcrita, somente exibida;

B.3 a transcrição representa o objeto correta ou incorretamente;

B.4 A transcrição não está fora de sua forma de representação;

C Se a forma de transcrição é a forma lógica, a transcrição é transcrição lógica.

D. A transcrição pode representar a realidade, mas não pode representar a forma lógica que tem em comum com ela para poder representá-la;

D.1 O que se exprime na linguagem não pode ser representado por meio dela;

D.1.1 A transcrição mostra a forma lógica da realidade.

4.2 há, em segundo lugar, uma operação de deciframento: a transcrição implica uma leitura do transcrito e, nesse caso, também é ela uma estrutura enunciativa. Afinal, não há texto que não para ser lido: há quem escreve, há o escrito e há quem lê. A transcrição é um texto que pede uma leitura. Também a operacão de deciframento supõe uma totalidade e que nela não seja lido mais do que aquilo que se pretendeu escrever. Trata-se de uma leitura do mostrado. Eis o segundo tempo do transcrever como ato de enunciação: o deciframento do mostrado.

5 Ao que foi dito no parágrafo 3.4 nada poderia ser objetado se não se considerasse que a transcrição, além de ser da ordem do mostrar, é também da ordem do dizer. Já se deixou entrever isso ao falar das duas operações implicadas na transcrição. Em ambas há um resto que escapa à formalização: há o resto que não cabe no ciframento, é o que permanece no objeto transcrito; há o resto que não cabe no deciframento, é o que permanece na transcrição. Nesse caso, parece possível supor que a transcrição é, ela mesma, um dizer na medida em que, sendo ela o mostrado de um dito, também ela teria sua instância mostrada já que é um dizer. 
E aqui se segue Lacan: a transcrição é uma espécie de matema, que na interpretação lacaniana não corresponde ao impedimento traçado por Wittgenstein para o mostrar. Se para Wittgenstein Sobre aquilo de que não se pode falar, deve-se calar, para Lacan, o que não pode ser dito por inteiro devemos bem-dizê-lo. Isso significa que sendo a transcrição um ato de enunciaço, tem ela seu aspecto mostrado e seu aspecto dito, ambos orientados duplamente, para o objeto a ser transcrito e para a transcrição como enunciação.

6 Sendo a transcrição, simultaneamente, um dizer e um mostrar, também la comporta, ao menos quanto ao seu aspecto de dizer, uma instância de enunciação e, ao menos quanto ao seu aspecto mostrado, uma instância de inefável.

7 A transcrição tem estatuto singular no campo da enunciação.

7.1 Transcrever é condicão da análise empreendida em lingüústica, sen-

do até mesmo uma etapa da análise.

7.2 A transcrição, vista como ato enunciativo, como um mostrar de um dizer que comporta, ela mesma, um outro dizer, pode ser estendida a estudos de diferentes corpora.

7.3 Cada transcrição é sempre única, singular e não linearmente extensível: é o efêmero da enunciação.

7.4 Não há integralidade na transcrição.

8 Algo permanece fora do campo do transcrito, à moda de um recalcamento. Afinal, transcrever é ato de produção de um dizer, é enunciar, e se há enunciação, há sujeito.

\section{BIBLIOGRAFIA}

BENVENISTE, E. Problemas de Lingüística Geral I. Campinas, São Paulo: Pontes, 1988. (col. Linguagem/crítica).

Problemas de Lingüística Geral II. Campinas, São Paulo: Pontes, 1989. (col. Linguagem/crítica).

DUCROT, O. "Dizível / Indizível". In: Enciclopédia Einaudi: LinguagemEnunciação. Lisboa: Imprensa Nacional-Casa da Moeda, 1984. p. 458476.

DUFOUR, D-R. Os mistérios da trindade. São Paulo: Companhia de Freud, 2000.

FLORES, V. Lingüística e Psicanálise: princípios de uma semântica da enunciação. Porto Alegre: EDIPUCRS, 1999.
FLORES, V; TEIXEIRA, M. Introdução à lingüuistica da enunciação. São Paulo: Ed. Contexto, 2005

LACAN, J. O Seminário; mais, ainda. Rio de Janeiro: Zahar, 1993. Livro 20. . O seminário; O avesso da psicanálise. Rio de Janeiro: Zahar, 1992. Livro 17.

GIANNOTTTI, J.A. Apresentação do Mundo: considerações sobre o pensamento de Ludwig Wittgenstein. São Paulo: Companhia da Letras, 1995.

MEYER, M. Lógica, Linguagem e Argumentação. Lisboa: Editorial Teorema, 1982

MILNER, J-C. A obra clara: Lacan, a ciência, a filosofia. Rio de Janeiro: Zahar, 1996.

ROUDINESCO, E. Jacques Lacan: esboço de uma vida, história de um sistema de pensamento. São Paulo: Companhia das Letras, 1994.

RUSSEL, B. “Introdução”. In: Wittgenstein, L. Tractatus Logico-Philosophicus. SP: Editora da Universidade de São Paulo, 1993.

SANTOS, L.H.L. "A essência da proposição e a essência do mundo". In: WITTGENSTEIN, L. Tractatus Logico-Philosophicus. São Paulo: Editora da Universidade de São Paulo, 1993.

SURREAUX, L. M. Linguagem, sintoma e clinica em clínica de linguagem. Tese de doutorado. Porto Alegre, IL/UFRGS, 2006.

WITTGENSTEIN, L. Tractatus Logico-Philosophicus. SP: Editora da Universidade de São Paulo, 1993. 